\title{
Case Report: Conversion of a Low-Flow to High-Flow Priapism
}

\author{
David Cahn Elliot Courter Gregory Diorio Michael Metro Phillip Ginsberg
}

Department of Urology, Einstein Healthcare Network, Philadelphia, PA., USA

\author{
Key Words \\ Priapism • Ischemic priapism • Non-Ischemic priapism
}

\begin{abstract}
Priapism is defined as an erection lasting for more than 4 hours and can be grouped into 3 distinct subtypes: ischemic (low-flow), stuttering and non-ischemic (high-flow). Herein, we present an interesting case of conversion from a low-flow to high-flow priapism after a distal shunting procedure. This is a rare phenomenon that has a paucity of documented cases. Diagnosis requires prompt clinical suspicion and confirmatory testing including penile cavernosal blood gases and Doppler ultrasound.

Copyright $\odot 2014$ S. Karger AG, Basel
\end{abstract}

\section{Case Report}

A 51-year-old African-American male presented to the emergency room with a painful erection that had been present for over 4 hours. The patient's past medical history included hypertension, hyperlipidemia, asthma, cerebrovascular accident, an appendectomy and an extensive previous history of priapism, with this episode being his 16 th over the last several years. Of note, he had a negative history for sickle cell disease or trait. He had never been shunted in the past, but had been detumesced with phenylephrine injections on a number of occasions. The patient denied use of alcohol, tobacco or drug use, however, a urine drug screen was positive for cocaine on a previous episode. Medications included albuterol, colace, aspirin and pravastatin. Additionally, the patient had been placed on daily oral Sudafed for priapism prophylaxis.

KARGER

Fax +4161306 1234

E-Mail karger@karger.ch

www.karger.com
(C) 2014 S. Karger AG, Basel

1015-9770/14/0082-0101\$38.00/0

Accessible online at:

www.karger.com/cur
The patient denied any history of PDE-5 inhibitor use or other erectile dysfunction pharmacotherapy. Despite the vast number of previous priapism episodes, the patient had not had outpatient urologic follow-up.

Physical exam revealed a fully erect penis with rigid corporeal bodies rigid that were tender to palpation, however the glans was soft. The remainder of his genitourinary exam was within normal limits. The patient's vital signs were stable, his abdomen was soft, and he had a well-healed McBurney incision in his right lower quadrant.

The diagnosis of ischemic priapism (IP) was confirmed by a penile cavernosal blood gas, which demonstrated a $\mathrm{pH}$ of 6.86 , $\mathrm{pCO}_{2}$ of $125 \mathrm{mmHg}$, and a $\mathrm{pO}_{2}$ of $9 \mathrm{mmHg}$. Given the patient's extensive history of recurrent priapism, we offered him a distal shunting procedure, to which he agreed.

A dorsal penile nerve block was performed in the standard fashion followed by superficial ring block. The patient was administered ceftriaxone $2 \mathrm{~g}$ and intravenous morphine. After the penis was prepped with betadine, a 14F Foley catheter was placed for urethral identification. A T-shunt procedure was preformed with two 11-blade stab incisions parallel to the urethra at the 3 and 9 o'clock positions followed by a $90^{\circ}$ twist away from the meatus to create a corproglandular shunt. A large amount of dark -deoxygenated blood was expressed from the erect penis until a flow of bright-oxygenated arterial blood was seen. After sufficient detumescence, the shunt incision sites were closed with vicryl suture and the Foley catheter was removed. Complete detumescence was initially achieved after the procedure, however, rigidity and partial tumescence returned again immediately thereafter. We assessed the patency of the distal shunt with the penile compression maneuver which resulted in repeated detumescence and re-filling.

A penile Doppler ultrasound was then ordered to evaluate penile blood flow. The ultrasound showed high velocity arterial flow in both cavernosal arteries with increased peak systolic velocities compared to a previous ultrasound as shown in figure1. Additionally, we performed a second blood gas analysis that revealed a $\mathrm{pH}$ 

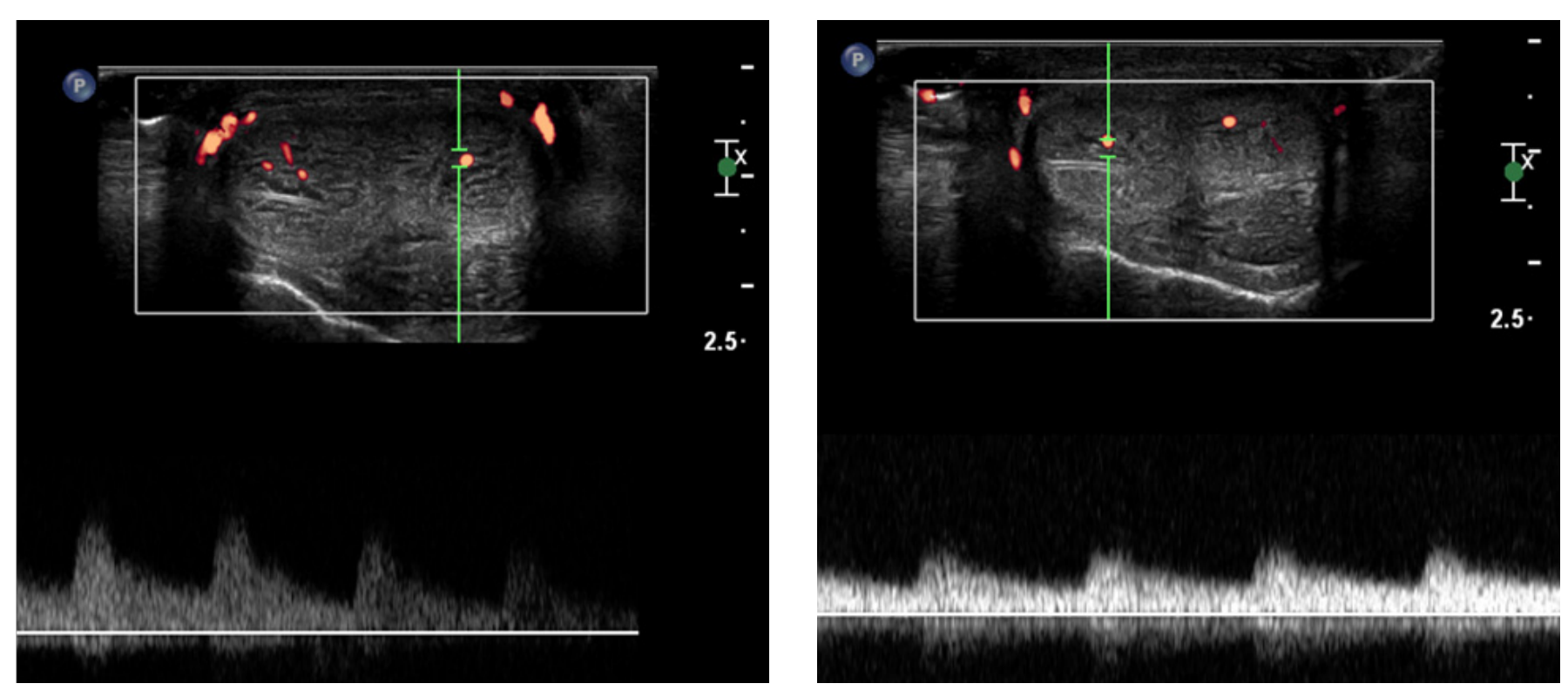

Fig. 1. Ultrasound with Doppler showing the left (left) and right (right) cavernosal arteries with adequate arterial flow during the high flow priapism.

of 7.40, a pCO of $39 \mathrm{mmHg}$, and a $\mathrm{pO}_{2}$ of $77 \mathrm{mmHg}$. Both the repeat blood gas and the penile ultrasound confirmed our suspicion that the patient now had a high-flow priapism. The patient was observed and his penis did detumesce prior to discharge. He was counseled on his cocaine use and we recommended abstinence from sexual activity to prevent any further episodes prior to his follow-up. The patient did follow-up in the urology clinic later that week with plans for a future penile prosthesis to prevent further episodes of priapism and preserve sexual function.

\section{Discussion}

Priapism is a potentially dangerous medical condition where the penis continues to be erect despite no continued stimulation. It is necessary to clinically categorize priapism into one of the 3 known subtypes of: ischemic (IP), non-ischemic (NP or high-flow), or stuttering (SP), as there are various levels of urgency and treatments for each. The initial evaluation is paramount and involves a detailed history and physical, cavernosal blood gases and penile Doppler ultrasound to assess and differentiate ischemic and non-ischemic priapism $[1,5]$.

IP is the most commonly seen subtype and is often associated with medications (anti-psychotics, anti-depressants, erectile dysfunction pharmacotherapy) or illicit drug use (cocaine, marijuana, ecstasy). Other endogenous factors include hypercoaguable states and blood cell dyscrasias (i.e. sickle cell anemia) [1,5]. Often, as was in our case, the exact etiology of the priapism may not be entirely clear. In IP, inhibition of venous outflow leads to arterial insufficiency, and emergent treatment is absolutely necessary to prevent long-term erectile dysfunction secondary to damaging fibrosis of the cavernosal bodies. Evaluation with cavernosal blood gas analysis is very important, as levels of $\mathrm{pH}<7.25, \mathrm{pCO}_{2}>60 \mathrm{mmHg}$ and $\mathrm{pO}_{2}<30 \mathrm{mmHg}$ are indicative of IP [5]. Initial treatment involves irrigation and aspiration of the corporeal bodies with an alpha-agonist such as phenylephrine, followed by more invasive distal and proximal shunting procedures if failure to achieve detumescence occurs $[1,5]$. Although rare, when detumescence is not achieved with the aforementioned procedures, it is essential to reassess for either the reoccurrence of IP or the conversion into high-flow non-ischemic state with proper diagnostic studies. NP is not a true urologic emergency and is much less common than IP. The etiology of NP is mostly attributed to trauma including: blunt or penetrating injury to the cavernous arteries, straddle injury, kicks to the perineum, and coital trauma. Although the penis is erect and rigid, it is usually not painful, and when assessed for oxygenation status the cavernosal blood gas shows a well-oxygenated picture with normal carbon dioxide levels. NP can be confirmed with Doppler ultrasound, which shows high arterial flow in the cavernosal arteries leading to the erect state of the 
penis. Although rare, etiology may be secondary to previous trauma or arteriovenous fistula, and unremitting high-flow priapism may necessitate arterial embolization $[1,4,5]$.

Stuttering or intermittent priapism (SP) is the third classification, which is described by a recurrent pattern of priapism episodes that can vary in both frequency and duration. It is most commonly associated with men who have sickle cell disease who can present in early childhood leading to multiple recurrent episodes throughout their adult life [1, 3]. Increasing frequency of episodes can be a signal to a major IP event, which may have been the case with our patient. Several different treatment options are available for SP including: daily oral $\alpha$-adrenergic therapy, GnRH analogues, oral finasteride, and interestingly, long-term dosing of PDE-5 inhibitors $[1-3,6]$.

The conversion of IP to NP, as is presented in this case is a very interesting phenomenon and a unique sub-variety of high-flow priapism. While the exact pathophysiologic mechanism is poorly understood, potential etiology includes essentially the creation of an iatrogenic arteriolar-sinusoidal fistula with shearing of the cavernosal ar- teries upon completion of distal shunting procedures [1, $4,5]$. A second mechanism may be due to disruption of the inherent vasorelaxing factors of the cavernosal system from ischemic insult during the IP episode $[1,7,8]$. Another possible mechanism may include local inflammatory vasodilatation from the release of nitric oxide and other cytokines leading to a reactive hyperemia.

\section{Conclusion}

We present an interesting case of a conversion from a low-flow to high-flow priapism after a distal shunting procedure. Differentiating the classification of the patient's priapism is of vital importance as the management differs for each type. With the use of a detailed history, physical exam, penile blood gas, and Doppler ultrasound, this can be carefully elucidated. If penile tumescence returns after shunting for an ischemic episode, the clinician should consider the possibility of a conversion into a high-flow non-ischemic state as was presented in this case.

\section{References}

1 Broderick G: Priapism; in Wein AJ, Kavoussi LR, Novick AC, Partin AW, Peters CA (eds): Campbell-Walsh Urology, ed 10. Philadelphia, Saunders, 2011, pp749-769.

-2 Burnett AL, Bivalacqua TJ, Champion HC, Musicki B: Long-term oral phosphodiesterase 5 inhibitor therapy alleviates recurrent priapism. Urology 2006;67:1043-1048.

3 Chow K, Payne S: The pharmacological management of intermittent priapismic states. BJU Int 2008;102:1515-1521.
Lutz A, LaCour S, Hellstrom W: Conversion of low-flow to high-flow priapism: a case report and review. J Sex Med 2012;9:951-954.

5 Montague DK, Jarow J, Broderick GA, Dmochowski RR, Heaton JP, Lue TF, Nehra A, Sharlip ID: American Urological Association guideline on the management of priapism. $\mathrm{J}$ Urol 2003;170:1318-1324.

6 6 Rachid-Filho D, Cavalcanti AG, Favorito LA, Costa WS, Sampaio FJ: Treatment of recurrent priapism in sickle cell anemia with finasteride: a new approach. Urology 2009;74: 1054-1057.
Seftel AD, Haas CA, Brown SL, Herbener TE, Sands M, Lipuma J: High flow priapism complicating veno-occlusive priapism: pathophysiology of recurrent idiopathic priapism? J Urol 1998;159:1300-1301.

8 Witt MA, Goldstein I, Saenz de Tejada I, Greenfield A, Krane RJ: Traumatic laceration of intracavernosal arteries: the pathophysiology of nonischemic, high flow, arterial priapism. J Urol 1990;143:129-132. 